\title{
Comparison of Hemoglobin A1c assay performance on two different commercial systems
}

Jozo Ćorić*, Elma Kučukalić, Berina Hasanefendić, Aleksandar Bodulović, Jasminka Mujić, Mirsad Panjeta

Department of Clinical Chemistry, University Clinical Center of Sarajevo, Bolnička 25, 71000 Sarajevo, Bosnia and Herzegovina

\begin{abstract}
Introduction: Glycated hemoglobin $(\mathrm{HbA} 1 \mathrm{c})$ is formed by non-enzymatic binding of glucose to the free amino group of the $\mathrm{N}$-terminal end of the $\mathrm{B}$-chain of hemoglobin $\mathrm{A}$. $\mathrm{HbA} 1 \mathrm{c}$ is representative of the mean blood glucose level over three months. The aim of the study was to evaluate the Hemoglobin A1c immunoturbidimetric assay performance on two different commercial systems.

Methods: We evaluated the precision and trueness for determination of HbA1c in whole blood. Concentrations of total hemoglobin and $\mathrm{HbA1}$ c were evaluated on Dimension Xpand (Siemens) and Cobas 501 (Roche) analyzers. $\mathrm{HbA} 1 \mathrm{c}$ was measured in a latex agglutination inhibition test. Commercial controls Liquichek Diabetes Control Level 1 and Liquichek Diabetes Control Level 2 (Bio Rad) at two levels were used for quality control. Analytical validation of $\mathrm{HbA} 1 \mathrm{c}$ included: within-run imprecision, between-day imprecision, inaccuracy and comparison determination on the human samples on 2 systems: Dimension Xpand and Cobas 501 analyzers.

Results: Within-run imprecision on the commercially controls for Level 1 is $4.5 \%$ and Level 2 is $3.2 \%$ between-day imprecision on commercially controls is $6.1 \%$ Level 1 and $5.1 \%$ Level 2 for respectively inaccuracy on commercially controls for Level 1 is $1.8 \%$ and Level 2 is $4.8 \%$. Method comparison on human samples shows the correlation coefficient of 0.99 .
\end{abstract}

Conclusion: The presented results of the analytical evaluation methods for the determination of $\mathrm{HbA} 1 \mathrm{c}$ showed an acceptable accuracy and precision.

Keywords: hemoglobin; HbA1c; diabetes mellitus; analysis comparison

\section{INTRODUCTION}

Glycated hemoglobin (HbA1c) is representative of the mean blood glucose level over three months.

\footnotetext{
*Corresponding Author: Jozo Ćorić, Department of Clinical Chemistry, University Clinical Center of Sarajevo, Bolnička 25, 71000 Sarajevo, Bosnia and Herzegovina,

E-mail: coricjozo@hotmail.com
}

Submitted: 10 March 2015/ Accepted: 8 April 2015

DOI: http://dx.doi.org/10.17532/jhsci.2015.233
HbA1c refers to the product of a non-enzymatic reaction between glucose and hemoglobin (1). The human erythrocyte is freely permeable to glucose, which can combine in non-enzymatic manner with hemoglobin to form HbAlc. This non-enzymatic reaction between the alpha-amino group of the $\mathrm{N}$-terminal valine of the hemoglobin beta-chain and glucose takes place to form an unstable aldimine of Schiff base intermediate. This reaction is slow and occurs at a rate that is proportional to the glucose concentration in the blood (1). 
A long time has passed since the discovery of $\mathrm{HbAlc}$ and its introduction in the laboratory practice related to the management of diabetes mellitus. Significant improvements have been achieved on the analytical side. HbA1c measurement have been used for 35 years. Around 100 different HbAlc methods have been used. They can be divided into two groups: the first group of $\mathrm{HbAlc}$ methods quantify glycated and non-glycated components (cation-exchange chromatography, agar gel electrophoresis); and the second group of HbAlc methods which separate glycated and non-glycated components based on structural differences (affinity chromatography and immunoassay). Most of these methods measure $\mathrm{HbA1c}$, while other methods quantify total glycated hemoglobin (2). Laboratory results may differ depending on the analytical technique, the age of the subject and biological variation among individuals (3).

First criteria for the diagnosis of diabetes mellitus were based on measuring blood glucose in non-pregnant adults (OGTT). In 1997 these criteria were supplemented with fasting plasma glucose (FPG). International Expert Committee for diagnosis and Management of Diabetes in 2009 recommended the $\mathrm{HbAl}$ c to be used as the preferred test for diagnosing type 2 diabetes (T2D). Diagnosis should be made on the $\mathrm{HbAlc}$ value $\geq 6.5 \%$ (48 $\mathrm{mmol} / \mathrm{mol})$ (5).

The objective of this study was to present the model for comparison of imunoturbidimetric test on two different types of automated biochemistry analyzers.

\section{METHODS}

\section{Patients}

The comparison of methods was made using the whole blood specimens (range of 3.0-14.9\% HBA1c) from a 20 patients with diabetes mellitus type 2 . The age range was $51.4 \pm 12.7$ years. Samples were taken in the period of one month at the Department of Biochemistry, Clinical Center of the University of Sarajevo.

\section{Assays}

The Dimension Xpand (Siemens) and Cobas e 501 (Roche) assays measure HbAlc and total hemoglobin. Measurement of the total hemoglobin is based on a modification of the alkaline hematin reaction while the HbA1c measurement is based on turbidimetric inhibition immunoassay (TINIA). Pretreatment is not necessary since method identifies only rearranged form of HbAlc. All forms of HbAlc which are glycated at the beta chain $\mathrm{N}$-terminus and have epitopes identical to HbA1c are measured. The relative proportion of the glycated HbA1c out of total HbA1c is calculated and reported.

The increase in absorption is inversely proportional to the concentration of $\mathrm{HbAlc}$ in the sample. Commercial controls Liquichek Diabetes Control Level 1 and Liquichek Diabetes Control Level 2 (Bio-Rad, USA) at two levels were used for quality control. Analytical validation of HbA1c included: within-run imprecision on the commercially controls $(\mathrm{N}=20)$; between-day imprecision commercially controls $(\mathrm{N}=25)$; inaccuracy on commercially controls $(\mathrm{N}=15)$ and comparison determination on the human samples on two systems.

\section{Statistical analysis}

The results were analyzed and expressed as means. Statistical test were performed by the statistical package Statistic for Windows (Stat for Windows, R. 4.5, USA). The correlation was analyzed by the Passing-Bablok linear regression test.

\section{RESULTS}

The inaccuracy of the HbA1c in series was determined in 15 measurements on commercially controls Liquichek Diabetes Control Level 1 and Liquichek Diabetes Control Level 2. The Dimension Xpand analyzer assay inaccuracy results are presented in Table 1.

The within-run precision of $\mathrm{HbAlc}$ was evaluated by analyzing a total 20 times during same day. A day-after-day precision measurement was carried out in the period of 10 days. The results of the Dimension Xpand analyzer assay precision within-run and between-run analyzes are shown in Table 2.

The Cobas 501 HBA1c assay was compared to the Dimension Xpand assay. Data from the study were analyzed using Passing-Bablok regression and are summarized in the Figure 1. 
TABLE 1. Inaccuracy of HbA1c assay

\begin{tabular}{lccc}
\hline Sample & $\begin{array}{r}\text { Expected } \\
\text { value (\%) }\end{array}$ & $\begin{array}{c}\text { Observed } \\
\text { value (\%) }\end{array}$ & $\begin{array}{c}\text { Inaccuracy } \\
\text { Bias (\%) }\end{array}$ \\
\hline $\begin{array}{l}\text { Liquichek diabetes } \\
\text { control level 1 }\end{array}$ & 5.40 & 5.31 & 1.8 \\
$\begin{array}{l}\text { Liquichek diabetes } \\
\text { control level 2 }\end{array}$ & 10.80 & 10.30 & 4.8 \\
\hline
\end{tabular}

TABLE 2. Precision of $\mathrm{HbA} 1 \mathrm{c}$ assay

\begin{tabular}{lccc}
\hline Sample & Mean value (\%) & SD & CV (\%) \\
\hline $\begin{array}{l}\text { Within-run } \\
\text { Liquichek diabetes } \\
\text { control level 1 }\end{array}$ & 5.35 & 0.24 & 4.5 \\
$\begin{array}{l}\text { Liquichek diabetes } \\
\text { control level 2 }\end{array}$ & 11.19 & 0.36 & 3.2 \\
$\begin{array}{l}\text { Between-run } \\
\text { Liquichek diabetes } \\
\text { control level 1 } \\
\text { Liquichek diabetes } \\
\text { control level 2 }\end{array}$ & 5.49 & 0.33 & 6.1 \\
\hline
\end{tabular}

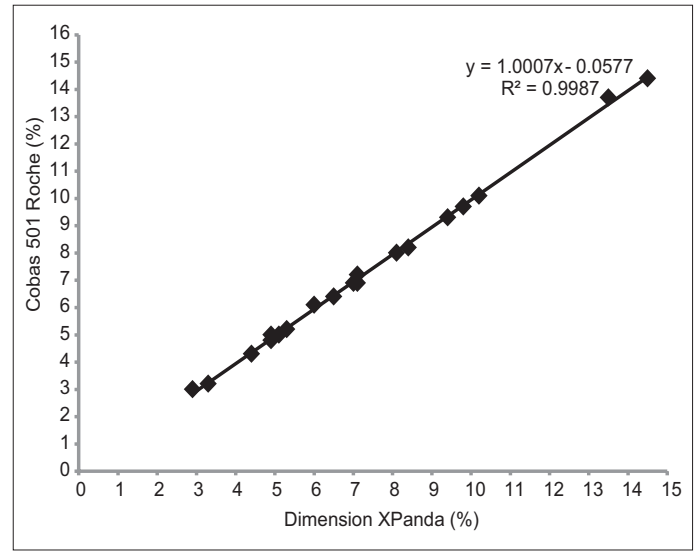

FIGURE 1. Correlation between the results of $\mathrm{HbA} 1 \mathrm{c}$ whole blood using Dimension Xpand and Cobas 501 Roche analyzers

On the whole range of measure, the two methods showed a good correlation $\left(\mathrm{R}^{2}=0.998\right)$.

\section{DISCUSSION}

Hemoglobin A1c is an indirect measure of the mean blood glucose level over the previous 2-3 months. The HbA1c assay provides a reliable measure of chronic glycemia (6). According to relevant clinical studies, HbA1c is a good predictor of microvascular complications (retinopathy, microalbuminuria and peripheral neuropathy). HbA1c has good predictive value in assessing the likelihood of developing diabetes in the future (7).

Assays for HbAlc have developed over years from assays with large uncertainties, to the current tests with a high degree of precision and trueness. The $\mathrm{HbA1c}$ results are now also used for the diagnosis of diabetes (8). According to American Diabetes Association (ADA) criteria the recommended order for diabetes testing is as follows: HbAlc, fasting plasma glucose (FPG) and OGTT. HbAlc-defined diabetes ranges are also a subject of debate, with some favoring $6.0-6.4 \%(42-47 \mathrm{mmol} / \mathrm{mol})$ (9).

The external quality control material must be as commutable as possible and should have a target value achieved with a reference method procedure. For tests used for the monitoring of diseases, the precision of the tests are often more important than the trueness. Long time stability of the internal QC $\mathrm{HbA1c}$ material is therefore of prime importance. Lyophilized materials are often materials, method dependent target values and acceptance limits have to be assigned to the materials. Sometimes locally defined target values and acceptance limits have to be applied (10).

One of the principal quality indicators in a medical laboratory is ensuring reliable and accurate results. The overall performance of the Dimension Xpand HbA1c assay was evaluated by determining precision, inaccuracy, and comparison. The HbAlc assay showed excellent results in all parameters evaluated in these studies. The Dimension Xpand analyzer assay showed excellent precision. The obtained CV\% values for the within-run were $3.2-4.5 \%$, which was in accordance with the manufacturers' recommendation (11). Between-day precision on commercially controls is 5.1-6.1 respectively slightly exceeded the manufacturers' recommendations. Inaccuracy on commercial controls for Liquichek Diabetes Control Level 1 is $1.8 \%$ and Liquichek Diabetes Control Level 2 is $4.8 \%$. Results of the comparison study showed no statistical difference according to the Passing Bablok regression analysis $(y=1.000 \mathrm{x}-0.057$,

$\mathrm{R}^{2}=0.998$; $\mathrm{x}$-represented Xpand assay and $\mathrm{y}$ - Cobas 501 assay).

The main finding of this study is that the presented model provides fast switch from one to another 
analytical system. With this algorithm continuous comparability and reliability of the HbA1c assays may be ensured (12). Although the most laboratory errors occure in pre-analytical or post-analytical phase (13), analytical errors due to system failure could be avoided with two equally ready and functional analyzers.

\section{CONCLUSION}

Imunoturbidimetric HbAlc assay of the Dimension Xpand and Cobas e501 analyzers demonstrate adequate performance characteristics for routine clinical use. The present results of the analytical evaluation methods for determination of HbAlc showed an acceptable accuracy and precision.

\section{CONFLICT OF INTEREST}

The authors declare no conflict of interest.

\section{REFERENCES}

1. Goldstein DE, Little RR, Wiedmeyer HM, England JD, McKenzie EM. Glycated hemoglobin: methodologies and clinical applications. Clin Chem 1986;32:64-70.

2. Topić E. Guidelines and recommendations for testing in diagnosis of diabetes mellitus: The role of HBA1c. Biochemia Medica 2014; 24(Suppl1):S17-S20.
3. Kilpatrick ES, Bloomgarden Z, Zimmet P. Is hemoglobin A1c a step forward for diagnosing of diabetes. BMJ 2009; 339:1288-90. http://dx.doi. org/10.1136/bmj.b4432.

4. Sack DB, Arnold M, Bakris GL, Bruns DE, Horvath AR, Kirkman MS, et al. Guidelines and Recommendations for Laboratory Analysis in the Diagnosis and Management of Diabetes Mellitus. Diabetes Care 2011; 34:61-99. http://dx.doi.org/10.2337/dc11-9998.

5. Nathan DM, Balkau B, Bonora E, Borch-Johnsen K, Buse JB, Colagiuri S. et al. International Expert Committee Report on the role of the $\mathrm{HbA} 1 \mathrm{C}$ assay in the diagnosis of diabetes, Diabetes Care 2009; 32:1327-34. http:// dx.doi.org/10.2337/dc09-1777.

6. Higgin T. HbA1c- An analyte of increasing importance. Clin Biochem 2012;45:1038-45. http://dx.doi.org/10.1016/j.clinbiochem.2012.06.006

7. Mandal Š, Ćaušević A, Malenica M, Hadžidedić Š. Age and gender related differences in free fatty acid levels in patients with type 2 diabetes mellitus. Journal of Health Sciences 2012; 11:184-191. http://dx.doi.org/10.17532/ jhsci.2012.37.

8. American Diabetes Association. Standards of medical care in diabetes. Diabetes Care 2011; 34:S11-S61. http://dx.doi.org/10.2337/dc11-S011.

9. Bucala R, Cerami A, Vlassara H. Advanced glycosylation end products in diabetic complications.Diabetes Rev 1995; 3: 258-68.

10. Jusupović F, Avdić D, Mahmutović J, Rudić A, Pašalić A, Branković $S$, Berić A, Mačak A. The presence of risk factors for diabetes mellitus type 2 in patients of family practice medicine. Journal of Health Sciences 2011; 1:23-28. http://dx.doi.org/10.17532/jhsci.2011.95.

11. Nordin G. HbA1c analyzing-challengers for the laboratory. Biochemia Medica 2014;24(Suppl 1):S21-S21.

12. Miller M, Šimundić A, Štefanović M, Ferene D. A model for results comparison on two different biochemistry analyzers in laboratory accredited according to the ISO 15 189. Biochemia Medica 2009:287-93. http://dx.doi. org/10.11613/BM.2009.027.

13. Plebani M. Laboratory errors: Haw to improve pre- and post- analytical phases. Biochem. Med. 2007; 15, 5-9. http://dx.doi.org/10.11613/ BM.2007.001. 